\title{
MENOS MULHERES, MENOS JOVENS, MAIS INCERTEZAS. A TRANSIÇÃO DEMOGRÁFICA NO BRASIL RURAL MERIDIONAL
}

\author{
Flávio Sacco dos Anios ${ }^{1}$ \\ Nádia Velleda Caldas ${ }^{2}$ \\ Germano Ehlert Pollnow ${ }^{3}$
}

\begin{abstract}
Resumo
Este artigo analisa o processo de masculinização e de envelhecimento da população rural dos estados meridionais do Brasil (Rio Grande do Sul, Santa Catarina e Paraná) a partir dos dados dos dois últimos censos demográficos. A ênfase dos autores está em discutir algumas de suas possíveis causas, demonstrar a importância destes fenômenos, assim como do debate em torno ao futuro da ruralidade nessa parte do país.
\end{abstract}

Palavras-chave: Transformações demográficas, Envelhecimento rural; Masculinização rural.

\section{FEWER WOMEN, FEWER YOUTH, MORE UNCERTAINTY. THE DEMOGRAPHIC TRANSITION IN RURAL SOUTHERN BRAZIL}

\begin{abstract}
This article analyzes the process of masculinization and aging population of rural southern states of Brazil (Rio Grande do Sul, Santa Catarina and Paraná) from the last demographic census data. The author"s emphasis is on the discussion of some of its possible causes and demonstrate the importance of these phenomena, as well as the debate on the future of rural life in this part of the country.

Key-words: Demographic changes, Rural masculinization, Rural aging, Rural Brazil southern.

\footnotetext{
${ }^{1}$ Graduação em Engenharia Agronômica (UFPEL). Mestrado em Sociologia (UFRGS). Doutorado em Agroecología Sociología y Estudios Campesinos pela Universidad de Córdoba - Espanha, UCO, Espanha. Prof. Adjunto da Universidade Federal de Pelotas (UFPEL). E-mail: saccodosanjos@gmail.com

${ }^{2}$ Bacharelado e Licenciatura em Ciências Sociais (UFPEL). Mestrado e Doutorado em Sistemas de Produção Agrícola

Familiar (UFPEL). Professora Adjunta da UniversidadeFederal de Pelotas (UFPEL). E- mail: velleda.nadia@gmail.com

${ }^{3}$ Graduando em Agronomia (UFPEL). E-mail:germanogp13@gmail.com
} 


\section{INTRODUÇÃO}

Radicalmente simples. São estes os adjetivos de que nos servimos para definir, de forma pragmática, a obra máxima elaborada pelo Prêmio Nobel de Economia (1998), Amartya Sen, intitulada "Desenvolvimento como liberdade". Para este economista indiano, o desenvolvimento há que ser visto como um processo através do qual se promova a eliminação de todas as formas de privação de liberdade que restringem as escolhas e as oportunidades das pessoas de exercerem, ponderadamente, sua condição de agente (SEN, 2000, p.20).

Tal concepção nos parece deveras fecunda para decifrar a situação de países como o Brasil, guindado em 2011, à condição de sexta economia do planeta, mas que simultaneamente ocupa postos nada confortáveis do ponto de vista de outros indicadores, a exemplo do acesso à educação, saúde, segurança pública, proteção social, etc. Em outras palavras, a realidade brasileira serve para ilustrar um dos aspectos mais destacados nas teses de Sen (2000), ao indicar as grandes divergências existentes entre crescimento econômico e desenvolvimento humano e social.

A liberdade de escolha dos indivíduos, segundo esta perspectiva, tem um valor intrínseco, a qual deve ser vista não somente como um fim a ser alcançado, mas como um meio de atingir o desenvolvimento, ampliando as oportunidades dos indivíduos. A pobreza deve ser vista "como uma privação de capacidades básicas, e não apenas como baixa renda" (SEN, 2000, p.35). Na nossa acepção, tal entendimento serve não somente para desnaturalizar essa grave mazela social, que incide sobre muitas localidades do Brasil, mas para repensar o papel do Estado e qualificar sua intervenção.

A abordagem de Sen nos ajuda a desvendar alguns enigmas que experimentam as sociedades contemporâneas. Nesse sentido, como é possível que um determinado grupo racial da maior economia do planeta - os afro-americanos tenha uma taxa percentual de sobrevivência, medida em anos de vida, inferior a das pessoas residentes em países cujas economias são imensamente inferiores, como é o caso da China, do estado indiano de Kerala, do Sri Lanka, Jamaica ou Costa Rica? Como demonstra Sen $(2000$, p.37), a renda per capita dos afroamericanos é consideravelmente mais baixa que a da população branca desse mesmo país.

Não obstante, os negros americanos, como adverte Sen, são muito mais ricos do que os habitantes da China ou de Kerala. A resposta a estas contradições há que ser buscada no fato de que os negros americanos não somente vivenciam uma privação relativa em termos de renda, comparativamente aos brancos, mas uma privação absoluta que é maior do que no caso dos demais países citados em termos de cobertura médica, serviços públicos de saúde, educação escolar e de oportunidades.

Vivemos num país de dimensões continentais, marcado por graves desigualdades sociais, e que não obstante alguns avanços recentes na área de segurança alimentar, acesso à energia elétrica, ao crédito, etc., tem se mostrado incapaz de remover diversas fontes de privações que experimentam os indivíduos, sobretudo os que vivem nos estados setentrionais do Brasil.

Do ponto de vista do âmbito rural, são flagrantes os indícios que apontam para o "déficit de cidadania" (VEIGA, 1997; 2001; SACCO DOS ANJOS, 2003) que acomete as coletividades ali residentes, em boa medida decorrente do peso de hierarquias sociais, como no caso das populações ribeirinhas, das comunidades remanescentes de quilombos, de pescadores artesanais e de outros atores desprovidos do exercício das liberdades substantivas de que fala o economista indiano. São recorrentes os casos, sobretudo nos estados do nordeste brasileiro, em que as pessoas são impedidas do acesso à educação por parte das velhas oligarquias rurais. Os dados do último censo agropecuário (2006) só fazem confirmar retrato de um Brasil rural que a maior parte dos brasileiros desconhece, sobretudo o 
com relação à incidência do analfabetismo, das dificuldades no acesso à assistência técnica, do trabalho escravo, etc.

Para os efeitos deste artigo importa destacar ainda outros aspectos. Nesse sentido, é fundamental mencionar que convencionalmente pesam sobre a agricultura, e sobre o mundo rural, um universo de representações sociais extremamente negativas do ponto de vista da natureza desta atividade, como referem alguns estudos, ao observar que no Brasil, e no continente latino-americano em geral, esse tipo de ofício é visto como próprio de pessoas para quem "la cabeza no le da para más" (ABRAMOVAY et al, 1998; CAMARANO e ABRAMOVAY, 1999). Mesmo nos estados meridionais do Brasil, onde há indiscutivelmente um maior nível de desenvolvimento social, medido através de indicadores de segunda e de terceira geração, a realidade pretérita e atual não foge deste quadro geral que associa o rural à precariedade e à falta de perspectivas.

Com efeito, não seria um exagero afirmar que estudo e agricultura são noções que se excluem mutuamente no imaginário das sociedades latino-americanas. Esse tipo de representação social se impõe de forma marcante nas mais diversas dimensões em que operam as relações sociais, tanto no âmbito das comunidades rurais quanto fora delas. No limite, condiciona as escolhas dos jovens rurais, cada vez menos propensos ao exercício desse tipo de profissão, influenciando, outrossim, os investimentos públicos na área da educação, melhoria das infraestruturas e outros fatores ligados ao mundo do conhecimento e da informação.

Afinal de contas, que razões haveria para modificar o script de um filme cujo desfecho, em princípio, seria dado de antemão a todos os brasileiros e brasileiras? Um desfecho que, por certo, nada tem de glorioso para as áreas rurais. Nesse sentido, há pouco mais de uma década Alves et al (1999, p.6-7), vaticinavam: "O Brasil tem, assim, os índices de urbanização dos países avançados e até os supera". Além disso, advertiam, nesse artigo, que em 2015 até as Regiões Norte e Nordeste atingirão as marcas dos países avançados. Como advertiu Abramovay (2003, p.17), "Esta constatação - lamentada como perda ou celebrada como sinal de progresso - é raramente contestada." Não deveria causar espanto o fato de que esta visão seja assumida, tout court, pelos meios de comunicação e pela opinião pública em geral. $O$ problema, segundo nossa perspectiva, é quando pesquisadores e estudiosos de temas agrários assimilam, acriticamente, tais pressupostos.

Destarte, os países da Organização para a Cooperação e Desenvolvimento Econômico (OCDE), e especialmente as nações que formam a União Europeia, decidiram escrever um „outro filme" que aponta numa direção exatamente oposta a estas posições, ao assumir que $80 \%$ de seu território deve ser considerado como rural $^{1}$. Essa mudança se dá no momento em que outros critérios são adotados para definir a ruralidade, os quais não levam em conta a centralidade da agricultura como atividade econômica e produtiva, mas sim, a densidade populacional. Para a OCDE, como alude Abramovay (2003, p.47), o critério da densidade demográfica, apresenta três vantagens básicas:

[...] trata-se de uma noção de fácil operacionalização e compreensão; sejam quais forem suas características, as áreas rurais serão sempre menos densamente povoadas que as urbanas; o critério de densidade é neutro e não remete a uma visão pré-determinada do que são os problemas e as possibilidades do rural: ela não induz à assimilação automática entre ruralidade e pobreza ou despovoamento, por exemplo.

\footnotetext{
${ }^{1}$ Ver a propósito os termos explicitados na Declaração de Cork (1996).
} 
Lamentavelmente, tais premissas não têm sido incorporadas, em nosso país nos debates e processos de reflexão sobre os destinos da ruralidade. Ainda que relevante esse tema foge aos objetivos deste artigo, que foi concebido a partir do esforço por evidenciar e analisar duas transformações demográficas que impactam, presentemente, sobre os estados meridionais do Brasil. Referimo-nos aos fenômenos de masculinização e envelhecimento da população rural e dos pequenos municípios dessa região do país.

Este trabalho, além dessa introdução, divide-se em quatro outras seções. A primeira delas expõe um quadro geral sobre a evolução demográfica do Brasil, das grandes regiões e estados da região sul do país do ponto de vista da situação de domicílio da população residente. Na segunda e terceira seções é onde se discute as transformações demográficas propriamente ditas. Como oportunamente veremos, trata-se de uma tendência que se aproxima bastante do quadro constatado em vários países do planeta, especialmente no caso da Europa, e que se converteu, como a seguir veremos, numa preocupação no marco das políticas de ordenamento territorial e das agências de desenvolvimento. A quarta e última seção reúne algumas considerações que julgamos pertinentes para ampliar a discussão a respeito do futuro dos espaços rurais no Brasil.

\section{A EVOLUÇÃO DEMOGRÁFICA RECENTE DO BRASIL}

Há alguns aspectos que devem ser destacados na evolução demográfica do Brasil no período correspondente aos últimos cinquenta anos. Como mostra a Figura 1 , nesse intervalo de tempo a população nacional foi multiplicada 2,7 vezes, passando de 70,99 para 190,7 milhões de habitantes. Não obstante, a população rural descendeu de 38,98 para 29,83 milhões de indivíduos.

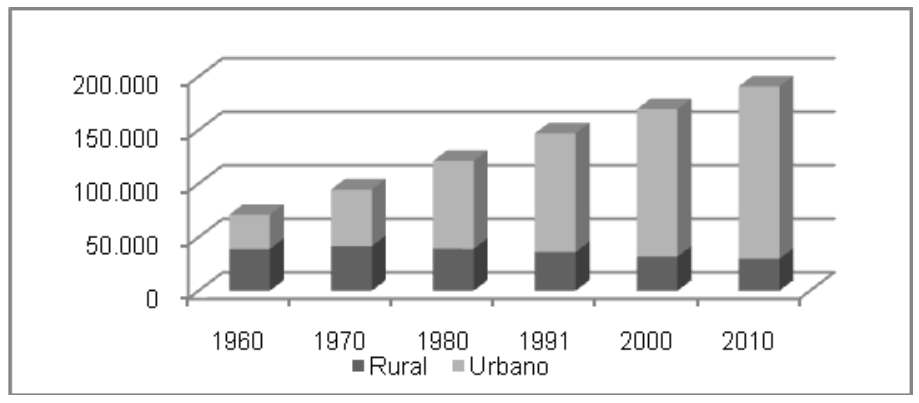

Figura 1 - Evolução da população brasileira por situação de domicílio (rural e urbano). Fonte: Censos Demográficos do IBGE (1960; 1970; 1980; 1991; 2000; 2010)

Ou seja, há um declínio em termos absolutos, mas, sobretudo relativos, se temos em mente que nos anos sessenta a proporção de brasileiros vivendo no campo $(55 \%)$ era maior do que nas cidades, ao passo que atualmente ela corresponde a escassos 15,6\%. Entrementes, o êxodo rural, decididamente, deixou de ser visto como um tema relevante nos estudos demográficos e sociais do Brasil, especialmente porque se considera como algo natural e esperado, tal como comentado na seção precedente.

O segundo aspecto que se deve enfatizar na transição demográfica brasileira tem a ver, indiscutivelmente, com o aumento na esperança de vida da população. "O Brasil está envelhecendo", segundo anunciado na mídia nacional, em 
meio à exaltação dos logros das políticas sociais do ponto de vista da melhoria do sistema de saúde, da ampliação de cobertura da previdência social, desde a promulgação da nova constituição (1988).

Há, por certo, um grande número de dados disponibilizados pelo IBGE a partir do último censo demográfico (IBGE, 2010) que nos permitem explorar outras perspectivas que são bastante úteis para esboçar esse quadro geral. Assim, como mostra a Tab. 1, se em 1991 a idade média dos brasileiros era de 26,5 anos, em 2010 ela alcança 32,1 anos. Mas se no meio urbano, para este mesmo intervalo de tempo, passamos de 27,1 para 32,3 anos, no meio rural a idade média passou de 24,8 para 30,6 anos.

Tabela 1 - Idade média da população total, urbana e rural nos censos demográficos de 1991 e 2010.

\begin{tabular}{l|cc|cc|cc}
\hline \multirow{2}{*}{$\begin{array}{l}\text { Grandes } \\
\text { Regiões }\end{array}$} & \multicolumn{2}{|c}{ Total } & \multicolumn{2}{c}{ Urbana } & \multicolumn{2}{c}{ Rural } \\
& 1991 & 2010 & 1991 & 2010 & 1991 & 2010 \\
\hline Brasil & 26,5 & 32,1 & 27,1 & 32,3 & 24,8 & 30,6 \\
Norte & 22,7 & 27,5 & 23,2 & 27,9 & 21,9 & 26,1 \\
Nordeste & 25,0 & 30,7 & 25,6 & 31,0 & 24,0 & 29,7 \\
Sudeste & 28,0 & 33,6 & 28,3 & 33,6 & 26,0 & 32,9 \\
Sul & 27,7 & 33,7 & 27,7 & 33,4 & 27,4 & 34,9 \\
Centro-este & 25,1 & 31,0 & 25,2 & 30,9 & 24,6 & 31,4 \\
\hline
\end{tabular}

Fonte: Censo Demográfico do IBGE (1991/2010).

A diferença de quase dois anos na idade média entre o âmbito rural e urbano há que ser imputada às conhecidas precariedades existentes nos espaços rurais do Brasil, sobretudo com relação ao acesso à água potável, saneamento e serviços de saúde no conjunto das regiões do país, sobretudo no caso da porção setentrional.

As idades médias mais elevadas estão nas regiões Sudeste e Sul do Brasil. Com efeito, se nos estados do Sul houve um incremento geral da ordem de 6 anos, no período intercensitário analisado (1991-2010), passando de 27,7 para 33,7 anos, a grande surpresa fica a cargo da população rural com um aumento da ordem de 7,5 anos, passando de 24,4 para 34,9 anos. Aqui fica uma primeira observação que deve ser sublinhada para os efeitos deste artigo. Referimo-nos ao fato que a idade média da população sulista rural supera em 1,5 anos à de sua própria população urbana. Os residentes rurais dos estados do Sul são, portanto, os que apresentam a idade média mais elevada dentre todas as regiões e recortes demográficos no intervalo de tempo analisado (1991-2010).

Por outra parte, os dados da Tab. 2 mostram a evolução da população urbana e rural nas cinco grandes regiões do Brasil, durante os últimos 50 anos, em termos absolutos. Como é possível perceber, atualmente o Nordeste brasileiro responde sozinho por $47,8 \%$ da população rural brasileira. 
Tabela 2 - Evolução da população urbana e rural nas grandes regiões brasileiras entre os censos demográficos de 1960, 1970, 1980, 1991, 2000 e 2010. (em 1.000 habitantes)

\begin{tabular}{llrrrrrr}
\hline $\begin{array}{c}\text { Grandes } \\
\text { Regiões }\end{array}$ & & 1960 & 1970 & 1980 & 1991 & 2000 & 2010 \\
\hline \multirow{2}{*}{ Norte } & Urbano & 1.041 & 1.784 & 3.399 & 5.932 & 9.003 & 11.665 \\
& Rural & 1.889 & 2.404 & 3.368 & 4.326 & 3.891 & 4.200 \\
\hline \multirow{2}{*}{ Nordeste } & Urbano & 7.681 & 11.981 & 17.960 & 25.753 & 32.929 & 38.821 \\
& Rural & 14.748 & 16.694 & 17.460 & 16.717 & 14.764 & 14.261 \\
\hline \multirow{2}{*}{ Centro } & Urbano & 995 & 2.358 & 4.950 & 7.649 & 10.075 & 12.483 \\
Oeste & Rural & 1.683 & 2.271 & 2.053 & 1.763 & 1.542 & 1.575 \\
\hline \multirow{2}{*}{ Sudeste } & Urbano & 17.819 & 29.347 & 43.551 & 55.149 & 65.442 & 74.696 \\
& Rural & 13.244 & 10.985 & 9.030 & 7.511 & 6.856 & 5.668 \\
\hline \multirow{2}{*}{ Sul } & Urbano & 4.469 & 7.434 & 12.154 & 16.393 & 20.307 & 23.261 \\
& Rural & 7.423 & 9.249 & 7.226 & 5.724 & 4.783 & 4.126 \\
\hline
\end{tabular}

Fonte: Instituto Brasileiro de Geografia e Estatística (IBGE), Censos Demográficos.

Essa região do Brasil, no último período intercensitário (2000/2010), experimentou um descenso populacional absoluto de apenas $3,4 \%$, ao passo que no Sudeste e Sul o mesmo dado alcançou $17,3 \%$ e $13,7 \%$, respectivamente. Contrariamente, as regiões Norte e Centro-Oeste houve um aumento da população rural da ordem de quase $8 \%$ e de $2 \%$, respectivamente.

O quadro demográfico relativo ao Nordeste brasileiro, com um sensível arrefecimento no êxodo rural e estabilização da população residente, é decorrente, dentre outros aspectos, do impacto gerado pelas mudanças operadas na previdência social rural, tal como indicaram diversos estudos (DELGADO e CARDOSO JÚNIOR,1999; FRANÇA, 2000; 2003; CALDAS et al, 2010) desde o final dos anos 1990, assim como das políticas de transferência direta de renda levadas a cabo durante a última década, as quais apontam para uma sensível ampliação da cobertura do sistema de seguridade social. Essas mudanças contribuíram para que muitas pessoas permanecessem no campo e/ou nas pequenas localidades. Este tema, ainda que relevante, escapa aos objetivos desse artigo.

Antes de entrar na discussão propriamente dita acerca do modo como se expressa a masculinização e o envelhecimento da população rural nos estados do Sul do Brasil, convém analisar a evolução da população rural e urbana em termos das unidades federativas que formam essa região do Brasil. Os dados da Tab. 3 cobrem o intervalo de tempo correspondente aos três últimos censos demográficos. Nesse sentido, observa-se que é entre 1991 e 2000 que ocorre a maior redução absoluta na população rural sulista, correspondente a um montante de quase um milhão de

\footnotetext{
${ }^{2}$ Referimo-nos, concretamente, às mudanças introduzidas a partir da Constituição de 1988, sobretudo à nova Lei Orgânica de Assistência Social (LOAS n 8.742/1993), que instituiu, entre outros aspectos: a) a extensão de benefícios à clientela "rural", até então pagos exclusivamente à "urbana"; b) a garantia do direito de aposentadoria às mulheres rurais ao atingirem 55 anos; c) a redução da idade mínima de 65 para 60 anos no caso dos homens para adjudicar-se o direito à aposentadoria em regime especial.
} 
pessoas. Sozinho o estado do Paraná responde por $50,3 \%$ deste contingente, seguido do Rio Grande do Sul $(29,0 \%)$ e de Santa Catarina $(20,7 \%)$.

Já no último período intercensitário (2000-2010) analisado, o êxodo rural na Região Sul ascende a 657.246, dando mostras, em termos absolutos, de um certo arrefecimento. A participação do Rio Grande do Sul, nesse contingente, equivale a $41,9 \%$, seguida do Paraná $(37,3 \%)$ e Santa Catarina (20,8\%). A mesma fonte indica que estas três unidades federativas apresentam uma situação muito semelhante do ponto de vista dos índices de urbanização. Nada menos que $85,3 \% ; 84,0 \%$ e $85,1 \%$ dos paranaenses, catarinenses e gaúchos, respectivamente, vivem nas cidades. No atual contexto, o Rio Grande do Sul é o estado da Região Sul com a maior população rural em termos absolutos. E se em 1991 aproximadamente um em cada três sulistas vivia no campo, vinte anos mais tarde um em cada sete pessoas fez essa mesma escolha.

Tabela 3 -Evolução da população urbana e rural nos Estados da Região Sul segundo os censos demográficos de 1991, 2000 e 2010. (em 1.000 habitantes)

\begin{tabular}{ccccccc}
\hline \multirow{2}{*}{ Estado } & \multicolumn{2}{c}{1991} & \multicolumn{2}{c}{2000} & \multicolumn{2}{c}{2010} \\
& Urbana & Rural & Urbana & Rural & Urbana & Rural \\
\hline PR & 6.193 & 2.250 & 7.782 & 1.777 & 8.913 & 1.532 \\
SC & 3.206 & 1.333 & 4.212 & 1.138 & 5.248 & 1.001 \\
RS & 6.994 & 2.141 & 8.313 & 1.869 & 9.100 & 1.594 \\
RSUL & 16.393 & 5.724 & 20.307 & 4.783 & 23.261 & 4.126 \\
\hline
\end{tabular}

Demográficos.

Fonte: Instituto Brasileiro de Geografia e Estatística (IBGE), Censos

A próxima seção é destinada à análise sobre o processo de masculinização nos estados da Região Sul do Brasil, um tema, que como a seguir veremos, mostrase igualmente carregado de significado pelas dúvidas que suscita nos debates sobre o destino da ruralidade nesta parte do país.

\section{MENOS MULHERES E MAIS INCERTEZAS: O DESEQUILÍBRIO DE GÊNERO NO BRASIL RURAL MERIDIONAL}

O desequilíbrio de gêneros tem sido identificado, desde os anos 1980 , em diversos estudos realizados em vários países, sobretudo no velho continente. Alguns trabalhos (BLANC e MACKINNON, 1990; HAUGEM e BERIT, 1994) associam esse fenômeno à própriamasculinização da atividade agropecuária , sobretudo a partir da entrada das máquinas agrícolas e do uso crescente de agrotóxicos. Todavia, é mister pensar que essa vinculação é sensivelmente afetada por aspectos de natureza cultural, religiosa e política.

O fato é que o mundo está em permanente estado de mutação e a questão de gênero, no espaço rural, evidentemente, não está imune às transformações que perpassam nossas sociedades. Já no começo dos anos 1990, Almås e Haugen (1991) estudaram a hipótese da masculinização, analisando os desafios futuros da agricultura norueguesa.

Nesse sentido, estudos levados a cabo por Shiva $(2000 ; 2001)$ buscam evidenciar a vinculação dos monocultivos à entrada de inovações tecnológicas, 
sobretudo dos organismos geneticamente modificados produzidos com o uso massivo de herbicidas; um fenômeno que se dá mediante a reiterada expulsão das mulheres do âmbito dos processos produtivos. Esta autora indiana chama a atenção para a "mentalidade bélica" da agricultura "produtivista", claramente estampada na nomenclatura dos herbicidas que aludem à guerra contra as plantas invasoras, insetos e a outras formas de vida consideradas "indesejáveis."

No caso espanhol, surgem vários estudos (SAMPEDRO, 1996; VÁZQUEZ e MAZARIEGOS, 1991; CAMARERO, 1997).reiterando que a discussão sobre gênero não pode ser vista fora de um marco mais amplo que aponta para a „desagrarização"das sociedades rurais. Um processo que se expressa, dentre outras formas, tanto em função da queda de peso específico da agricultura na composição da riqueza nacional, quanto na capacidade declinante de ocupar a força de trabalho.

Mas há outros estudos que identificam situações onde o exercício de atividades profissionais alheias à agricultura tem sido responsável por ampliar o universo de possibilidades das mulheres rurais, propiciando, inclusive, que muitas delas optem por permanecer no campo. O exercício da pluriatividade (combinação de atividades agrícolas e não agrícolas por membros das unidades familiares de produção) poderia servir como instrumento para modificar relações de poder no seio das explorações agrárias (EVANS e ILBERY, 1996:76), ou mesmo induzir a que ocorram certas rupturas na hierarquia familiar, especialmente se tais iniciativas ou práticas são desempenhadas por outros membros (esposa, filhos) e não propriamente pelo titular da exploração familiar.

Estudos como os de Deseran e Simpkins (1991); Symes (1991); Almås e Haugen (1991) tratam de associar o desenvolvimento de novas atividades, levadas a cabo no interior ou no exterior do estabelecimento, especialmente as que geram ingresso econômico, com uma melhora substancial na condição hierárquica feminina, e numa sensível redução do peso do patriarcalismo. Estudos mais recentes realizados na Espanha (Camarero e SamPedro, 2008) asseveram que a questão da masculinização do espaço rural converteu-se, nesse país, num "problema endêmico", fato que no nosso entendimento, não pode ser visto como uma exceção, mas sim, como um quadro recorrente e que reivindica um novo olhar sobre a realidade rural.

No Brasil o tema da masculinização do campo só muito recentemente converteu-se em objeto da reflexão científica através de estudos (FROELICH et al 2011, SACCO DOS ANJOS e CALDAS, 2013; CAMARANO e ABRAMOVAY, 1999; SCHNEIDER, 1994). que se baseiam, fundamentalmente, na análise das estásticas oficiais. Nesse sentido, Nesse sentido, à luz dos últimos dados censitários, caberia indagar: em que medida essa tendência se mantém nos estados meridionais do Brasil? Existe alguma semelhança com a situação experimentada nos países europeus em termos de sua intensidade? O que nos dizem os dados do último censo demográfico?

Os dados da Tab. 4 indicam os índices de masculinização (número de mulheres para cada 100 homens), no estado do Rio Grande do Sul, segundo faixas de idade e situação do domicílio (urbano e rural), nos três últimos censos demográficos. De um modo geral, há uma tendência que se mantém durante os vinte últimos anos. 
Tabela 4 - Índices de masculinização da população do Rio Grande do Sul, segundo dados dos censos 1991, 2000, 2010 e faixas de idade.

\begin{tabular}{crrrrrr}
\hline Idade & \multicolumn{2}{c}{1991} & \multicolumn{2}{c}{2000} & \multicolumn{2}{c}{2010} \\
(anos) & Urbana & Rural & Urbana & Rural & Urbana & Rural \\
\hline 0 a 9 & 96,6 & 95,0 & 96,6 & 95,2 & 96,5 & 95,3 \\
10 a 19 & 100,0 & 89,6 & 98,2 & 90,6 & 98,2 & 91,6 \\
20 a 29 & 107,4 & 86,4 & 102,4 & 87,1 & 101,6 & 87,7 \\
30 a 39 & 108,0 & 88,7 & 108,2 & 87,8 & 105,3 & 89,8 \\
40 a 49 & 108,5 & 89,5 & 109,6 & 87,8 & 111,0 & 86,0 \\
50 a 59 & 115,0 & 92,9 & 113,7 & 90,4 & 114,9 & 87,0 \\
60 a 69 & 130,9 & 94,1 & 130,0 & 92,9 & 124,7 & 88,2 \\
70 a 79 & 153,5 & 107,8 & 156,5 & 110,2 & 150,5 & 104,5 \\
80 e mais & 202,5 & 137,9 & 209,9 & 142,6 & 212,1 & 146,3 \\
\hline
\end{tabular}

Fonte: Censos Demográficos do IBGE (1991, 2000, 2010).

Se a população rural se masculiniza, a população urbana experimenta um comportamento exatamente oposto. No caso urbano, a supremacia numérica das mulheres cresce desde a faixa dos 30-39 anos e atinge seu ápice no estrato superior aos oitenta anos onde seu número é mais que o dobro dos homens em função da maior longevidade feminina. No caso rural, a população feminina supera a masculina apenas nos dois estratos superiores de idade (70-79 e 80 e mais) pelo mesmo motivo.

Não obstante, chamamos a atenção para os estratos 40-49 anos, 50-59 e 6069 onde há, claramente, um declínio ininterrupto no número de mulheres rurais em relação ao de homens. Estes grupos representam um estrato etário onde há uma intensa atividade laboral e social. No caso rural, o exercício de tarefas domésticas inclui, normalmente, tanto o cuidado dos filhos e netos quanto das tarefas agrícolas, das roças e das criações de autoconsumo, que culturalmente, são assumidas pelas mulheres.

Através dos dados da Tab. 5 vemos a situação do Paraná com relação ao mesmo indicador. Vemos que o quadro geral de masculinização do campo e de feminização urbana tem se mantido praticamente inalterado ao longo dos dois últimos lustros. Todavia, chamamos a atenção para o intervalo correspondente a 60-69 anos onde o índice de masculinização é máximo. Há apenas 60,8 mulheres para cada 100 homens no meio rural paranaense, sendo que no meio urbano tem-se praticamente o dobro $(119,2)$ deste índice nesta mesma faixa etária. Em verdade, somente no estrato de pessoas com 80 e mais anos é que o número de mulheres supera ao de homens no estado do Paraná. 
Tabela 5 - Índices de masculinização da população do Paraná, segundo dados dos censos 1991, 2000, 2010 e faixas de idade.

\begin{tabular}{ccccccc}
\hline $\begin{array}{c}\text { Idade } \\
\text { (anos) }\end{array}$ & \multicolumn{2}{c}{1991} & \multicolumn{2}{c}{2000} & \multicolumn{2}{c}{2010} \\
\hline 0 a 9 & 96,9 & 96,0 & 96,2 & 95,1 & 96,8 & 95,3 \\
10 a 19 & 102,0 & 92,1 & 99,2 & 90,2 & 98,1 & 90,8 \\
20 a 29 & 108,2 & 89,9 & 104,1 & 89,4 & 102,1 & 89,9 \\
30 a 39 & 110,1 & 91,2 & 108,6 & 90,9 & 106,3 & 92,4 \\
40 a 49 & 105,0 & 88,7 & 110,4 & 87,9 & 110,4 & 89,1 \\
50 a 59 & 106,3 & 84,2 & 110,2 & 86,9 & 115,0 & 87,3 \\
60 a 69 & 112,6 & 78,9 & 115,5 & 80,4 & 119,2 & 60,8 \\
70 a 79 & 118,2 & 82,9 & 122,6 & 84,9 & 126,4 & 86,6 \\
80 e mais & 134,3 & 95,2 & 146,4 & 102,4 & 155,6 & 103,9 \\
\hline
\end{tabular}

Fonte: Censos Demográficos do IBGE (1991, 2000, 2010).

A Tabela. 6 mostra a situação relativa ao estado de Santa Catarina. Nesta unidade federada vemos que a desproporção entre gêneros no âmbito rural cresce, entre os três últimos censos demográficos, nas faixas etárias correspondentes a 40 49; 50-59 e 60-69 anos. De forma muito semelhante ao que acontece no Rio Grande do Sul, o número de mulheres para cada 100 homens é superior somente a partir dos 70-79 anos e 80 anos e mais.

O corte rural-urbano é bastante criticado nos estudos demográficos realizados no Brasil por diversos motivos. Um deles deriva do entendimento de que muitas pequenas localidades, distantes das médias e grandes cidades, possuem características eminentemente rurais do ponto de vista da densidade demográfica e da grande importância das atividades agropecuárias na ocupação da população, assim como pela escassez de empresas do ramo industrial e de serviços. É por esse motivo que buscamos explorar uma outra abertura dos dados censitários, analisando o índice de masculinização segundo o tamanho dos municípios.

Tabela 6 - Índices de masculinização da população de Santa Catarina, segundo dados dos censos 1991, 2000, 2010 e faixas de idade.

\begin{tabular}{crrrrrr}
\hline \multirow{2}{*}{ Idade (anos) } & \multicolumn{2}{c}{1991} & \multicolumn{2}{c}{2000} & \multicolumn{2}{c}{2010} \\
& Urbana & \multicolumn{1}{c}{ Rural } & Urbana & Rural & Urbana & Rural \\
\hline 0 a 9 & 96,5 & 95,0 & 96,3 & 96,3 & 96,3 & 94,5 \\
10 a 19 & 100,9 & 92,2 & 98,5 & 90,7 & 97,7 & 92,7 \\
20 a 29 & 104,8 & 86,9 & 101,9 & 89,3 & 98,9 & 88,2 \\
30 a 39 & 103,8 & 88,8 & 104,5 & 88,3 & 101,6 & 91,7 \\
40 a 49 & 101,8 & 91,7 & 104,4 & 88,8 & 106,2 & 87,1 \\
50 a 59 & 107,0 & 94,2 & 106,9 & 92,3 & 109,1 & 89,4 \\
60 a 69 & 118,7 & 94,6 & 119,0 & 95,4 & 116,7 & 91,0 \\
70 a 79 & 129,8 & 98,6 & 137,9 & 103,3 & 136,4 & 105,3 \\
80 e mais & 157,9 & 120,0 & 173,2 & 123,6 & 183,3 & 132,5 \\
\hline
\end{tabular}

Fonte: Censos Demográficos do IBGE (1991, 2000, 2010). 
Essa é a informação reunida nos dados da Tab. 7. Como é possível perceber, no estado do Rio Grande do Sul há, claramente, uma tendência no qual o número de mulheres é bastante mais baixo nas localidades de até 5 mil habitantes e entre 5 e 8 mil habitantes. Nesse sentido, conforme cresce o tamanho de municípios, cresce proporcionalmente o número de mulheres para cada 100 homens, chegando a um máximo $(109,4)$ no estrato correspondente a 100.001 e mais habitantes. Essa é, em última análise, outra forma através do qual pode-se perceber a masculinização das áreas rurais e da feminização das cidades.

Tabela 7 - Número de homens e mulheres e Índices de masculinização da população do Rio Grande do Sul, segundo número e tamanho dos municípios.

\begin{tabular}{cccccc}
\hline $\begin{array}{c}\mathrm{N}^{\circ} \\
\text { Habitantes }\end{array}$ & $\begin{array}{c}\mathrm{N}^{\circ} \\
\text { Munic. }\end{array}$ & Habitantes & Homens & Mulheres & $\begin{array}{c}\text { Índice } \\
\text { Masc. }\end{array}$ \\
\hline Até 5.000 & 227 & 678.89 & 344.787 & 334.103 & 96,9 \\
\hline $\begin{array}{c}5.001 \text { a } 8.000 \\
8.001 \text { a } 10.000\end{array}$ & 19 & 536.224 & 269.839 & 266.385 & 98,7 \\
\hline $\begin{array}{c}10.001 \text { a } \\
15.000\end{array}$ & 43 & 514.089 & 256.653 & 257.436 & 100,3 \\
\hline $\begin{array}{c}15.001 \text { a } \\
20.000\end{array}$ & 22 & 392.601 & 193.796 & 198.805 & 102,6 \\
\hline $\begin{array}{c}20.001 \text { a } \\
30.000\end{array}$ & 30 & 720.38 & 355.497 & 364.883 & 102,6 \\
\hline $\begin{array}{c}30.001 \text { a } \\
50.000\end{array}$ & 28 & 1.021 .237 & 503.889 & 517.348 & 102,7 \\
\hline $\begin{array}{c}50.001 \text { a } \\
100.000\end{array}$ & 24 & 1.663 .011 & 809.572 & 853.439 & 105,4 \\
\hline 100.001 e mais & 18 & 5.000 .962 & 2.387 .972 & 2.612 .990 & 109,4 \\
\hline TOTAL & 496 & 10.693 .929 & 5.205 .057 & 5.488 .872 & 105,5 \\
\hline \multicolumn{5}{c}{ Fonte: Censos Demográficos do IBGE $(2010)}$. &
\end{tabular}

Os dados da Tab. 8 mostram a situação do Paraná. Diferentemente do Rio Grande do Sul, o equilíbrio entre homens e mulheres só é alcançado a partir dos estratos superiores (15.001 a 20 mil habitantes), sendo máximo o índice de masculinização $(106,7)$ nos dezoito municípios com 100.001 e mais habitantes. No estado de Santa Catarina, como mostra a Tab. 9, o mesmo índice se aproxima da situação verificada no estado do Paraná. Todavia, vemos que é somente a partir dos estratos superiores de população (acima de 20 mil habitantes) que o número de mulheres para cada 100 homens começa a crescer, até um máximo de quase 104 nos municípios com mais de 100 mil habitantes.

O fato é que o fenômeno de masculinização rural vem sendo detectado desde há muito tempo, como assim demonstra estudo clássico de Sorokin e Zimmerman (1929) nos Estados Unidos da América dentro daquela tradição de estudos rurais tão criticada por seus vínculos com a concepção dicotômica. Para estes autores norte-americanos haveria quatro causas fundamentais para este fenômeno. A primeira delas seria a correlação entre urbanização e feminização urbana, motivada pela demanda específica de mão de obra em distintos centros urbanos, e que acarreta, ao fim e ao cabo, uma migração fortemente seletiva. A segunda causa seria a natureza familiar da atividade agrícola, que unicamente 
permite à mulher uma inserção laboral de caráter doméstico. A terceira causa tem a ver com uma suposta preferência feminina pela vida urbana, enquanto que a quarta e última tem a ver com as formas de transmissão do patrimônio fundiário que claramente tendem a excluir as mulheres desse processo.

Tabela 8 - Número de homens e mulheres e Índices de masculinização da população do Paraná, segundo número e tamanho dos municípios.

\begin{tabular}{cccccc}
\hline $\begin{array}{c}\mathrm{N}^{\circ} \\
\text { Habitantes }\end{array}$ & $\begin{array}{c}\mathrm{N}^{\circ} \\
\text { Munic. }\end{array}$ & Habitantes & Homens & Mulheres & $\begin{array}{c}\text { Índice } \\
\text { Masc. }\end{array}$ \\
\hline Até 5.000 & 98 & 349.093 & 176.318 & 172.775 & 98,0 \\
\hline 5.001 a 8.000 & 84 & 532.722 & 269.635 & 263.087 & 97,6 \\
\hline 8.001 a 10.000 & 21 & 183.601 & 92.516 & 91.085 & 98,5 \\
\hline $\begin{array}{c}10.001 \mathrm{a} \\
15.000\end{array}$ & 77 & 948.549 & 477.874 & 470.675 & 98,5 \\
\hline $\begin{array}{c}\text { 15.001 a } \\
\text { 20.000 }\end{array}$ & 32 & 553.364 & 276.542 & 276.822 & 100,1 \\
\hline $\begin{array}{c}20.001 \mathrm{a} \\
\text { 30.000 }\end{array}$ & 27 & 647.922 & 320.986 & 326.936 & 101,9 \\
\hline $\begin{array}{c}30.001 \mathrm{a} \\
\text { 50.000 }\end{array}$ & 28 & 1.029 .665 & 509.171 & 520.494 & 102,2 \\
\hline $\begin{array}{c}\text { 50.001 a } \\
\text { 100.000 }\end{array}$ & 14 & 1.048 .277 & 515.936 & 532.341 & 103,2 \\
\hline 100.001 e mais & 18 & 5.151 .333 & 2.492 .016 & 2.659 .317 & 106,7 \\
\hline TOTAL & 399 & 10.444 .526 & 5.130 .994 & 5.313 .532 & 103,6 \\
\hline
\end{tabular}

Fonte: Censos Demográficos do IBGE (2010).

Tabela 9 - Número de homens e mulheres e Índices de masculinização da população de Santa Catarina, segundo número e tamanho dos municípios.

\begin{tabular}{|c|c|c|c|c|c|}
\hline $\begin{array}{c}\mathrm{N}^{\circ} \\
\text { Habitantes }\end{array}$ & $\begin{array}{c}\mathrm{N}^{\circ} \\
\text { Munic. }\end{array}$ & Habitantes & Homens & Mulheres & $\begin{array}{l}\text { Índice } \\
\text { Masc. }\end{array}$ \\
\hline Até 5.000 & 108 & 341.26 & 175.222 & 166.038 & 94,8 \\
\hline 5.001 a 8.000 & 43 & 278.98 & 141.875 & 137.105 & 96,6 \\
\hline 8.001 a 10.000 & 21 & 188.58 & 95.564 & 93.016 & 97,3 \\
\hline $\begin{array}{c}10.001 \mathrm{a} \\
15.000\end{array}$ & 40 & 481.047 & 242.975 & 238.072 & 98,0 \\
\hline $\begin{array}{c}15.001 \mathrm{a} \\
20.000\end{array}$ & 20 & 337.981 & 169.91 & 168.071 & 98,9 \\
\hline $\begin{array}{c}20.001 \mathrm{a} \\
30.000\end{array}$ & 20 & 473.822 & 235.647 & 238.175 & 101,1 \\
\hline $\begin{array}{c}30.001 \mathrm{a} \\
50.000\end{array}$ & 14 & 537.479 & 265.83 & 271.649 & 102,2 \\
\hline $\begin{array}{c}50.001 \mathrm{a} \\
100.000\end{array}$ & 15 & 943.957 & 466.274 & 477.683 & 102,4 \\
\hline 100.001 e mais & 12 & 2.665 .330 & 1.307 .063 & 1.358 .267 & 103,9 \\
\hline TOTAL & 293 & 6.248 .436 & 3.100 .360 & 3.148 .076 & 101,5 \\
\hline
\end{tabular}

Fonte: Censos Demográficos do IBGE (2010). 
Com o sugestivo título "Por que se van las mujeres?" Camarero e Sampedro (2008) analisam a masculinização rural na Espanha, chamando a atenção para a importância deste processo. Para indagar sobre suas causas, apoiam-se na análise da evolução de distintas cohortes de nascidos em municípios rurais e seu comportamento em função de nível de estudo, situação laboral e práticas de mobilidade laboral.

As conclusões a que chegam estes autores são no sentido de mostrar que os processos de "arraigo" e de „desarraigo" das mulheres rurais estão intimamente relacionados com as oportunidades de trabalho e o acesso à mobilidade espacial. Nesse sentido, a condição de commuter (trabalhador que viaja diariamente para trabalhar num centro urbano e retorna para o âmbito rural ao final da jornada) depende, obviamente, das condições de infraestruturas viárias e da própria estrutura de oportunidades.

Nos Estados de Santa Catarina (SEYFERTH, 1974; SACCO DOS ANJOS, 1995) e Rio Grande do Sul (Schneider, 1999) essa situação (commuter) já foi relatada em estudos que aludem ao caso de comunidades rurais em que os trabalhadores ali residentes, sejam eles homens ou mulheres, exercem a condição do que se conhece como "colonos-operários" empregados em fábricas dos mais diversos ramos da atividade industrial (confecção, metalúrgicas, calçados, alimentação, etc.). Nesse caso, e somente nesses casos, o exercício de atividade laboral não implica, necessariamente, na expulsão definitiva das mulheres em idade ativa para o âmbito das cidades, tal como indicado nas tabelas precedentes.

Mas a questão é que se trata de regiões de maior densidade industrial, onde é bastante complexa a tarefa de delimitar onde começa o ambiente urbano e onde termina o rural. Outrossim, no Sul do Brasil o fenômeno da masculinização responde a um conjunto de causas que tem a ver, entre outros aspectos, com uma situação generalizada de precariedade estrutural da maior parte das pequenas localidades, mesmo no caso dessa parte do país. A „masculinização da agricultura", sobretudo com o advento das tecnologias da revolução verde, é um dos fatores, que indiscutivelmente, obra em favor da „masculinização rural". Há, nesse sentido, outros estudos, como o de Haugen e Brandth (1994), que argumentam que a saída das mulheres há que ser imputada à impossibilidade de levar a cabo, na atual conjuntura, uma agricultura menos produtivista, mais ecológica e em harmonia com a natureza.

Analisando esse fenômeno no caso do Rio Grande do Sul, Brumer (2004) concluiu que a desigualdade de gêneros responde a uma série de fatores com ênfase na posição subordinada das mulheres no âmbito da exploração familiar, bem como a outros fatores externos (estrutura de oportunidades no plano regional). O fato é que a saída definitiva das mulheres jovens remete à busca por ampliar os horizontes e de romper com os grilhões em que se fecha a própria agricultura, sobretudo nas regiões mais afastadas dos grandes centros urbanos, e ao exercício de papéis que invariavelmente não são reconhecidos pelos homens e pela sociedade em geral. Por mais extenuantes que sejam as jornadas de trabalho, as mulheres „sempre ajudam"os homens e raramente são vistas como protagonistas destes processos.

A questão da escolaridade tanto pode ser vista como causa, quanto consequência no que tange a explorar as razões da diáspora feminina. Nas áreas rurais do Sul do Brasil, como indicam dados recentes (DIESE, 2009), a escolaridade média dos homens é de 5,5 anos, ao passo que das mulheres (a mais alta dentre todas as regiões do Brasil) é de 5,7. Ainda que pequena, a diferença de escolaridade das mulheres em relação aos homens pode favorecê-las na busca por um emprego externo que, nesse caso, implica a saída em definitivo da comunidade em que 
residem. Por outra parte, também é certo que essa busca por ampliar seu universo social, e de dar continuidade aos estudos, estimula a saída. No caso das mulheres em idade mais avançada, a permanência no espaço rural tem sido favorecida pela possibilidade de adjudicar-se uma aposentadoria, tal como mencionamos na seção precedente.

O fato é que no âmbito europeu o celibato não representa nenhuma novidade. Na França é referido desde há muitos tempo(BOURDIER,1983), ao passo que na Espanha, além dos trabalhos aqui mencionados, este assunto tem sido objeto explorado, inclusive, como argumento de filmes ${ }^{3}$, que, para além do lado trágico e irônico reiterado em desconcertantes narrativas, escancara a complexidade de um quadro que atualmente preocupa as autoridades desse país, tal como referem Camarero e Sampedro (2008) em seu estudo.

O que aqui se quer enfatizar é que os dados não deixam dúvidas acerca da extensão de um fenômeno que até então era visto como próprio da Europa e/ou daquelas nações que experimentaram um padrão de urbanização muito anterior e bastante distinto ao do Brasil, sobretudo do ponto de vista da capacidade de ocupar a população migrante. Destarte, o quadro evidenciado nos estados meridionais do país é muito similar, ainda que responda a causas não exatamente idênticas. Examinemos agora a segunda transformação demográfica que nos cabe analisar nesse artigo.

\section{MIGRAM OS MAIS JOVENS, RESTAM MAIS INCERTEZAS}

A divulgação dos dados do último censo agropecuário (2006) só fazem confirmar as suspeitas acerca da grave ameaça que paira sobre o futuro de diversas regiões do Sul do país, sobretudo naquelas marcadas pela importância social e econômica da agricultura familiar. No estado do Rio Grande do Sul a mesma fonte estima que dos 441,5 mil estabelecimentos rurais ali existentes, nada menos que $31,3 \%$ não possuem mais jovens vivendo na propriedade rural.

Já havíamos comentado na seção 2 deste artigo acerca da idade média (mais elevada) dos indivíduos no meio urbano e rural dos estados do sul em relação ao resto do país. Analisemos agora, com maior detalhamento, as diferenças existentes nessa parte do país em relação à média nacional, considerando também o corte urbano rural.

Os dados da Tab. 10 expõem a transição demográfica operada no Brasil nos últimos vinte anos, com uma clara tendência ao envelhecimento, tanto no âmbito urbano quanto rural. Mas no Sul do país isso ainda é mais evidente se consideramos que, nesse caso, a proporção de idosos (mais de 65 anos), no âmbito urbano, saltou de 4,90 para $7,84 \%$, ao passo que no meio rural passou-se de 5,14 para $9,49 \%$. No Rio Grande do Sul o mesmo dado chega a $11,56 \%$, ou seja, quase o dobro do que havia em 1991.

Por outro lado, há outro dado que suscita certa preocupação nos estados meridionais, qual seja o pronunciado declínio do que podemos considerar como sendo o segmento mais importante da população ativa (15 a 64 anos), quando comparamos o âmbito urbano e rural. Nos censos de 1991; 2000 e 2010 esse coletivo corresponde, no âmbito urbano da região sul como um todo, a respectivamente $63,64 \%$; $66,69 \%$ e

\footnotetext{
${ }^{3}$ Ao célebre filme norteamericano "Westward the Women" (1951), dirigido por William A. Wellman, soma-se o instigante "Flores de otro mundo" (1999) de Iciar Bollaín, retratando o caso de um „pueblo castellanomanchego", onde além do problema aqui discutido, outros temas como o choque cultural, racismo e solidão são magistralmente retratados nesta produção espanhola.
} 
$70,41 \%$. Todavia, no âmbito rural o mesmo dado equivale a respectivamente $61,62 \%$; $64,38 \%$ e $68,02 \%$.

Com isso, o que se quer aqui afirmar é que, se por um lado, o aumento na esperança de vida há que ser saudado como um aspecto bastante positivo nessa transição demográfica, também é certo que aos problemas relativos à sucessão hereditária nos estabelecimentos rurais, soma-se agora um outro problema relativo ao declínio na força de trabalho ativa no ambiente rural.

Com relação ao estrato extremamente jovem (0-14 anos) percebe-se algumas diferenças dignas de nota entre os âmbitos urbano e rural da região sul do Brasil. Esse coletivo que representava $31,46 \%$ da população urbana em 1991, passou para $27,27 \%$ em 2000 e $21,75 \%$ em 2010 . Todavia, no âmbito rural tem-se, respectivamente, $33,24 \% ; 28,59 \%$ e $22,5 \%$. Todavia, em estados como o Rio Grande do Sul constata-se que a proporção deste setor da população jovem é sempre inferior, no meio rural, que no correspondente ao meio urbano, nos três últimos censos demográficos.

\section{Tabela 10 -Distribuição da população urbana e rural segundo faixas de idade nos três estados da região sul do Brasil.}

\begin{tabular}{|c|c|c|c|c|c|c|c|}
\hline & & & Brasil & RS & SC & PR & $\begin{array}{c}\text { Região } \\
\text { Sul }\end{array}$ \\
\hline \multirow{9}{*}{ URBANA } & \multirow{3}{*}{$\begin{array}{l}0 \text { a } 14 \\
\text { anos }\end{array}$} & 1991 & 32,93 & 30,09 & 32,59 & 32,43 & 31,46 \\
\hline & & 2000 & 28,36 & 26,12 & 27,83 & 28,20 & 27,27 \\
\hline & & 2010 & 23,23 & 20,96 & 21,61 & 22,62 & 21,75 \\
\hline & \multirow{3}{*}{$\begin{array}{c}15 \text { a } 64 \\
\text { anos }\end{array}$} & 1991 & 62,19 & 64,31 & 63,15 & 63,12 & 63,64 \\
\hline & & 2000 & 65,75 & 67,01 & 67,06 & 66,16 & 66,69 \\
\hline & & 2010 & 69,40 & 70,15 & 71,76 & 69,92 & 70,41 \\
\hline & \multirow{3}{*}{$>65$ anos } & 1991 & 4,88 & 5,60 & 4,26 & 4,45 & 4,90 \\
\hline & & 2000 & 5,90 & 6,87 & 5,11 & 5,64 & 6,04 \\
\hline & & 2010 & 7,37 & 8,90 & 6,63 & 7,47 & 7,84 \\
\hline \multirow{9}{*}{ RURAL } & \multirow{3}{*}{$\begin{array}{l}0 \text { a } 14 \\
\text { anos }\end{array}$} & 1991 & 40,30 & 29,96 & 34,33 & 35,73 & 33,24 \\
\hline & & 2000 & 35,08 & 25,83 & 29,58 & 30,98 & 28,59 \\
\hline & & 2010 & 28,64 & 20,16 & 22,85 & 24,52 & 22,50 \\
\hline & \multirow{3}{*}{$\begin{array}{c}15 \text { a } 64 \\
\text { anos }\end{array}$} & 1991 & 55,04 & 63,42 & 61,05 & 60,16 & 61,62 \\
\hline & & 2000 & 59,21 & 65,56 & 64,11 & 63,36 & 64,38 \\
\hline & & 2010 & 63,94 & 68,28 & 68,60 & 67,44 & 68,02 \\
\hline & \multirow{3}{*}{$>65$ anos } & 1991 & 4,66 & 6,62 & 4,62 & 4,11 & 5,14 \\
\hline & & 2000 & 5,71 & 8,61 & 6,31 & 5,66 & 7,03 \\
\hline & & 2010 & 7,42 & 11,56 & 8,55 & 8,04 & 9,49 \\
\hline
\end{tabular}

Fonte: Censos demográficos do IBGE (1991, 2000, 2010).

Nesse artigo interessa-nos analisar, de modo especial, um estrato da população rural muito importante quando pensamos no futuro das áreas rurais. Referimo-nos ao grupo que aqui chamaremos "rapazes e moças", entendido como sendo formado por pessoas com idades compreendidas entre 15 e 24 anos. É sobre os ombros deste coletivo que recai o futuro dos 849 mil estabelecimentos familiares identificados no último censo agropecuário (IBGE, 2006) no conjunto dos três estados meridionais. 
Todavia, os dados relativos aos três últimos censos demográficos projetam sombras e incertezas que merecem ser frisadas nesse artigo. Os dados da Tab. 11 mostram o percentual de rapazes e moças no âmbito urbano e rural em relação ao conjunto da população masculina e feminina dos três estados meridionais. Como é possível perceber, até 1991 a proporção de rapazes e moças no meio rural era superior a que existia no meio urbano.

Não obstante, a situação se inverte claramente se temos em mente que no ano 2000 os rapazes e moças rurais representavam, respectivamente, $17,8 \%$ e $17,1 \%$ da população rural, enquanto que no meio urbano o mesmo dado correspondia a $19,3 \%$ e $18,4 \%$. Por fim, em 2010, chegamos a uma situação extrema, quando no meio rural a proporção de rapazes e moças equivale a respectivamente $16,1 \%$ e $15,6 \%$, ao passo que no meio urbano o mesmo dado corresponde a $17,9 \%$ e $16,8 \%$. O que estes dados mostram, com bastante clareza, é que a redução na proporção de jovens impacta mais fortemente sobre o meio rural que sobre o meio urbano.

Tabela 11 - Participação percentual da população jovem (idade entre 15 e 24 anos de idade) no conjunto da população masculina e feminina urbana e rural dos estados do Rio Grande do Sul, Santa Catarina e Paraná nos três últimos censos demográficos $(1991,2000,2010)$.

\begin{tabular}{rrrrr}
\hline \multirow{2}{*}{ Censos } & \multicolumn{2}{c}{ Urbanos } & \multicolumn{2}{c}{ Rurais } \\
& Rapazes & Moças & Rapazes & Moças \\
\hline 1991 & 18,7 & 18,6 & 19,7 & 19,1 \\
2000 & 19,3 & 18,4 & 17,8 & 17,1 \\
2010 & 17,9 & 16,8 & 16,1 & 15,6 \\
\hline
\end{tabular}

Fonte: Censos demográficos do IBGE $(1991,2000,2010)$.

Além disso, há outros elementos que merecem ser enfatizados. Nesse sentido, a mesma fonte indica que, em 1991, em termos absolutos, o número de rapazes superava ao de moças em 68.721 , considerando os três estados juntos. Já no censo 2000 o mesmo dado correspondia a 55.579, e dez anos mais tarde, a 40.327. Ou seja, a diferença de jovens em favor do sexo masculino tem se mantido, não obstante a diminuição generalizada nas taxas de incremento demográfico, tal como aludido anteriormente. Essa constatação é claramente observável a partir dos dados da Tab. 12.

Há, portanto, um predomínio claramente jovem e feminino no marco de um processo de mudança social que pouca atenção tem recebido por parte dos estudiosos da sociedade brasileira. Num dos primeiros estudos a abordar esse tema, Camarano e Abramovay (1999) já alertavam para a estreita associação entre esse êxodo rural, claramente seletivo, e a questão do acesso (ou do não acesso) aos serviços básicos da cidadania. 
Tabela 12 - Número de rapazes e moças (idade compreendida entre 15 e 24 anos de idade) nos três estados do Sul, nos três últimos censos demográficos, e razão de sexos, medida a partir do quociente entre rapazes e moças.

\begin{tabular}{ccccccc}
\hline \multirow{2}{*}{ Censos } & \multicolumn{3}{c}{ Urbanos } & \multicolumn{3}{c}{ Rurais } \\
& Rapazes & Moças & $\begin{array}{c}\text { Razão } \\
\text { de } \\
\text { Sexos }\end{array}$ & Rapazes & Moças & $\begin{array}{c}\text { Razão } \\
\text { de } \\
\text { Sexos }\end{array}$ \\
\hline 1991 & 1.491 .886 & 1.565 .965 & 0,95 & 591.046 & 522.33 & 1,13 \\
2000 & 1.904 .856 & 1.918 .906 & 0,99 & 445.238 & 389.66 & 1,14 \\
2010 & 2.017 .817 & 2.014 .459 & 1,00 & 347.388 & 307.06 & 1,13 \\
\hline
\end{tabular}

Fonte: Censos demográficos do IBGE (1991, 2000, 2010).

Desnecessário dizer que temos no Brasil indicadores educacionais muito precários, mesmo no caso dos estados meridionais, sobretudo no que afeta às condições sociais do ambiente rural e das pequenas localidades. Há, nesse sentido, uma grande questão que até bem pouco tempo ocupava a mente de agências internacionais de desenvolvimento e, mui especialmente, dos agentes de extensão rural. Trata-se de um trade off de importância inquestionável, que coloca, frente a frente, duas posições claramente antagônicas. De um lado, os que defendem uma melhoria profunda no acesso à educação e o direito a uma escola de qualidade nestes âmbitos, ampliando assim as possibilidades dos jovens desenvolverem todas as suas potencialidades, dentro ou fora do espaço rural.

Todavia, no extremo oposto estão aqueles setores da sociedade que acreditam que o fortalecimento do acesso à educação representa a "antecâmara da partida em direção às cidades", como bem resumiram Camarano e Abramovay (1999, p.20) em seu estudo. De todos modos, parece impensável aceitar a naturalidade de um processo que diária e silenciosamente remete às cidades uma legião de jovens que buscam ampliar os horizontes sociais em que se fecha a agricultura e o mundo rural na atualidade.

Não resta dúvida de que a questão da saída prematura destes jovens responde a um conjunto de causas extremamente amplo e complexo. Não é somente em busca de educação e de oportunidades de exercício profissional que os jovens deixam o campo. A conhecida canção dos Titãs (Comida), sucesso dos anos 1980, serve de inspiração para entender esse enigma, sobretudo quando seus autores nos brindam com versos como: "A gente não quer só comida, A gente quer comida, diversão e arte. A gente não quer só comida, a gente quer saída para qualquer parte".

O "Qualquer parte" nestes versos pressupõe, na alusão que aqui fazemos, poder ir além das fronteiras, que até bem pouco tempo atrás, estavam circunscritas ao espaço local. Destarte, são inegavelmente profundas as transformações impostas pela sociedade da tecnologia e da informação. Não obstante, não parecem ter sido suficientemente fortes para mudar o imaginário social construído em torno à ideia de que o exercício da profissão de agricultor, ou de agricultora, é incompatível com uma boa formação educacional. Longe estamos de modificar essa espúria associação.

Mas afinal, como deveria ser o ensino e a educação prestada aos jovens rurais, filhos de agricultores de sua comunidade? Não se trata de uma simples questão retórica, mas sim, de uma das perguntas incluídas no questionário adotado 
na Pesquisa AFDLP (2005) realizada por pesquisadores ligados a duas universidades (UFPel e UFRGS) em quatro microrregiões do Rio Grande do Sul. Os dados da Tab. 13 são bastante eloquentes porque mostram que a opção da maior parte dos entrevistados (quase 2/3) é por „uma educação mista, que contemple tanto o exercício da atividade agrícola quanto de atividades fora da agricultura".

Os autores desta pesquisa mostram que não há diferenças substanciais entre regiões marcadas por uma grande disponibilidade de empregos e de oportunidades para o exercício de atividades alheias à agricultura, como é o caso de Veranópolis, na Serra Gaúcha, e em outras partes deste estado brasileiro onde esse fato não ocorre com tanta facilidade, como é o caso de Morro Redondo (extremo sul) ou em Três Palmeiras, no extremo setentrional gaúcho.

Como indica a Tab. 13, os que desejam uma educação essencialmente voltada para as atividades agropecuárias representam $18,9 \%$ do total, havendo como situações como Três Palmeiras (23,7\%) e Salvador das Missões $(20,7 \%)$ onde há percentuais mais elevados. Nesse sentido, por mais desejosos que os pais, por ventura estejam, de que o negócio familiar prossiga, estão eles igualmente conscientes da necessidade urgente de preparar os filhos para deixar o campo em face das razões e circunstâncias que foram aqui expostas. Uma educação mista, destinada a preparar os filhos tanto para a agricultura quanto para outras profissões é, indiscutivelmente, a opção mais importante $(63,9 \%$ no total).

Tabela 13 - Distribuição da opinião dos entrevistados quando perguntados sobre como deveria ser o ensino e a educação prestada aos jovens rurais, filhos de agricultores em quatro microrregiões da geografia gaúcha.

\begin{tabular}{|c|c|c|c|c|c|}
\hline $\begin{array}{l}\text { Como deveria ser a } \\
\text { educação? }\end{array}$ & $\begin{array}{c}\text { Total } \\
\text { (Geral) }\end{array}$ & Veranópolis & $\begin{array}{l}\text { Morro } \\
\text { Redondo }\end{array}$ & $\begin{array}{l}\text { Salvador } \\
\text { das } \\
\text { Missões }\end{array}$ & $\begin{array}{c}\text { Três } \\
\text { Palmeiras }\end{array}$ \\
\hline $\begin{array}{l}\text { Voltada para as } \\
\text { atividades agrícolas }\end{array}$ & 18,9 & 18,6 & 12,9 & 20,7 & 23,7 \\
\hline $\begin{array}{l}\text { Orientada a preparar } \\
\text { os jovens para } \\
\text { disputar trabalhos e } \\
\text { empregos fora da } \\
\text { agricultura }\end{array}$ & 10,1 & 13,6 & 11,3 & 10,3 & 5,1 \\
\hline $\begin{array}{l}\text { Uma educação } \\
\text { mista, destinada } \\
\text { tanto à agricultura } \\
\text { como à formação } \\
\text { geral }\end{array}$ & 63,9 & 64,4 & 69,4 & 62,1 & 59,3 \\
\hline $\begin{array}{l}\text { Não sabe/sem } \\
\text { resposta }\end{array}$ & 7,1 & 3,4 & 6,5 & 6,9 & 11,9 \\
\hline Total & 100,0 & 100,0 & 100,0 & 100,0 & 100,0 \\
\hline
\end{tabular}

Fonte: Pesquisa AFDLP (2005).

\footnotetext{
4 Trata-se de pesquisa financiada pelo CNPq, intitulada "Agricultura Familiar, Desenvolvimento Local e Pluriatividade: a emergência de uma nova ruralidade no Rio Grande do Sul". Ver a propósito: Schneider (2006); Schneider et al (2006).
} 


\section{CONSIDERAÇÕES FINAIS}

Para sublinhar a gravidade das transformações demográficas que afetam o meio rural do velho continente, são comumente utilizadas expressões tais como desertização ou desertificação. Naturalmente, não no sentido ecológico ou agronômico do termo (depauperação progressiva dos solos), mas sim, no afã de mostrar a conversão de muitas áreas, onde antes pululava a vida econômica e social, em regiões formadas por imensos desertos marcados pelo abandono e pela ausência de habitantes.

O paradoxo e a ironia estão justamente no fato de existirem inúmeros "desertos verdes", como no caso das grandes áreas de monoculturas florestais (eucaliptos, pinus, etc.), onde velhas casas e edificações teimosamente resistem, ao sabor das intempéries e da ação do tempo, nas quais, inevitavelmente, não há mais vida, não há mais gente. A atual crise econômica que acomete o mundo, e mais duramente, os países do velho continente, tem sido responsável por desatar uma série de discussões que aludem, por exemplo, ao padrão de ordenamento territorial vigente desde meados dos anos 1980.

Nesse sentido, não deveria causar surpresa a posição assumida pela Organização Internacional do Trabalho (OIT) ao defender a tese de que a reativação das áreas rurais deveria ser vista como uma espécie de catalisador do crescimento econômico e da geração de empregos. Este debate, por mais relevante que seja, foge completamente aos objetivos que traçamos ao elaborar esse artigo.

Nossa intenção foi no sentido de mostrar que certas transformações, que até então se admitia como típicas de certos países e regiões do planeta estão incidindo, com certa intensidade, nos três estados da região Sul do Brasil. Lamentavelmente, pouca atenção tem sido dada ao assunto, seja por parte dos cientistas sociais, seja do Estado, seja das próprias organizações agrárias do ponto de vista de suas pautas de atuação.

O efeito combinado da queda na taxa de fecundidade e do aumento na esperança de vida explicam, em boa medida, um quadro de envelhecimento da população brasileira em geral. Todavia, chama a atenção o fato de que tal processo incide mais intensamente no âmbito rural que no urbano nessa parte da geografia nacional. Por outra parte, igualmente preocupante é o desequilíbrio de gêneros, especialmente quando se percebe que nos últimos vinte anos o êxodo rural é claramente jovem e feminino.

Conhecer os fatores subjacentes às transformações demográficas aqui enfocadas requer um olhar que transcenda a mera contemplação destes dados como se fosse uma fatalidade. Um olhar que se atreva a mergulhar no universo das representações sociais e dos valores que orientam as escolhas dos indivíduos, seja por parte daqueles que decidem migrar, seja dos que decidem permanecer em seus locais de origem.

Se pensarmos no desenvolvimento, como advertiu Sen (2000), enquanto expansão de liberdades substantivas, e na remoção de toda sorte de privações que sofrem os indivíduos, a saída a ser buscada no enfrentamento do quadro aqui exposto, passa, inexoravelmente, pela capacidade que temos de gestar novos instrumentos que ampliem o universo de possibilidades postas ao alcance da população rural, tanto para aqueles que desejam viver como agricultores como para os que desejam exercer outras atividades. No limite, poder-se-ia dizer que desagrarização não pressupõe, necessariamente, desruralização. 


\section{REFERÊNCIAS BIBLIOGRÁFICAS}

ABRAMOVAY, R. Funções e medidas da ruralidade no desenvolvimento contemporâneo. In: ABRAMOVAY, R. O Futuro das Regiões Rurais. Porto Alegre: UFRGS Editora, 2003.

ABRAMOVAY, R.; BALDISSERA, I. T.; CORTINA, N.; FERRARI, D.; SILVESTRO, M.; TESTA, $V$. M. Juventude e agricultura familiar: desafios dos novos padrões sucessórios. Chapecó, Brasília: Convênio FAO-INCRA/CPPP-EPAGRI - Edições UNESCO, 1998.

ALMÅS, Reidar \& Marit; HAUGEN S. Norwegian gender roles in transition: the masculinization hypothesis in the past and in the future. Journal of Rural Studies, London, v. 7, No.1/2, pp 79-83, 1991.

ALVES, E.; LOPES, M.; CONTINI, E. O empobrecimento da agricultura brasileira. Revista de Política Agrícola, Brasília, ano 8, n. 3, p.5-19, 1999.

BLANC, M.; MACKINNON, N. Gender relations and the family farm in western Europe. Journal of Rural Studies, London, ${ }^{\circ}$ 6. p. 401-405, 1990.

BOURDIEU, P. Le sens pratique. Paris: Éditions de Minuit, 1983.

BRASIL, Instituto Brasileiro de Geografia e Estatística, IBGE. Disponível em: <http://www.ibge.gov.br/ibgeteen/datas/mulher/mulherhoje.html.> Acesso em: 5 outubro 2012.

BRASIL, Instituto Brasileiro de Geografia e Estatística, IBGE. Censo Demográfico, 2010.

BRASIL, Instituto Brasileiro de Geografia e Estatística, IBGE. Censo Agropecuário 2006. Rio de Janeiro.

BRASIL, DIEESE. Departamento Intersindical de Estatística e Estudos socioeconômicos. Núcleo de Estudos Agrários e Desenvolvimento Rural, Ministério do Desenvolvimento Agrário. Estatísticas do Meio Rural, São Paulo, 2011.

BRUMER, A. Gênero e agricultura: a situação da mulher na agricultura do Rio Grande do Sul. Estudos Feministas, Florianópolis, 12(1), 205-227, 2004.

CALDAS, N V;SACCO DOS ANJOS, Flávio; BEZERRA, Antônio Jorge Amaral. Agricultura familiar e previdência social: implicações de uma política pública no Rio Grande do Sul. Raízes (UFPB), Campina Grande, v. 30, nº 2, p. 84-99, 2010. 
CAMARANO, A.; ABRAMOVAY, R. Êxodo rural, envelhecimen to e masculinização no Brasil: panorama dos últimos cinquenta anos. In: Texto para Discussão. $n^{\circ} 621$, IPEA: Rio de Janeiro, 23p., 1999.

CAMARERO RIOJA, L. Pautas Demográficas y Espaciales de las Transformaciones del medio rural: Ruralidad y Agricultura. In: GOMES BENITO, C.; GONZÁLEZ RODRÍGUEZ, J.J. (eds), Agricultura y sociedad en la agricultura en la España contemporánea. Madrid: MAPA, 1997.

CAMARERO RIOJA, Luís.; SAMPEDRO GALLEGO, Rosario. ¿Por qué se van las mujeres? El continuum de movilidad como hipótesis explicativa de la masculinización rural. In: Revista Española de Investigaciones Sociológicas, Madrid, n. ${ }^{0} 124$, p. 73105, 2008.

CARNEIRO, M .J. Herança e gênero entre agricultores familiares Estudos Feministas, Florianópolis, v. 9, $\mathrm{n}^{\circ} 1$, p. 22-55, 2001.

DELGADO, G. C. e CARDOSO JR, J. C. O Idoso e a Previdência Rural no Brasil: A Experiência recente da Universalização. Rio de Janeiro: IPEA, 1999.

EVANS, N. J. e ILBERY, B. W. Exploring the Influence of Farm based Pluriactivity on Gender Relations in Capitalist Agriculture. Sociologia Ruralis, Netherlands, v.XXXVI, $\mathrm{n}^{\circ}$ 1, p. 74-92, 1996.

DESERAN, F., SIMPKINS, N. Women"s off-farm work and gender stratification. Journal of Rural Studies, London, v. 7, n 1-2. p. 91-97, 1991.

FRANÇA, A. S. A Previdência Social e a Economia dos Municípios. $2^{\mathrm{a}}$ ed. Brasília: ANFIP, 2000. 243p.

FRANÇA, A. S. A importância da previdência social na economia dos municípios brasileiros e o resgate da cidadania. In: BRASIL, Ministério da Previdência Social, Conjuntura Social, V. 14, nº 1, Brasília: MPS, ACS. p.15-40, 2003.

FROEHLICH, José Marcos, RAUBER, Cassiane da Costa; CARPES, Ricardo Howes; TOEBE, Marcos. Éxodo seletivo, masculinização e envelhecimento da população rural na região central do RS. Ciência Rural, Santa Maria, v.41, nº 9, p. 1674-1680, 2011.

HAUGEN, M. \& BERIT, B.Gender differences in modern agriculture. The case of women farmers in Norway. Gender \& Society, London, v. 8, n² 2, p. 206-229, 1994.

SACCO DOS ANJOS, F. A Agricultura Familiar em transformação: $\mathbf{O}$ caso dos colonos-operários de Massaranduba, Santa Catarina. Pelotas: Editora da UFPEL, 1995. 
SACCO DOS ANJOS, F. Agricultura Familiar, Pluriatividade e Desenvolvimento Rural no Sul do Brasil. Pelotas: EGUFPEL, 2003.

SACCO DOS ANJOS, F; CALDAS, Nádia Velleda. Cambios demográficos en el Brasil meridional: la masculinización, el envejecimiento y la desagrarización de la población rural. Perspectivas Sociales/Social Perspectives, Nuevo León, México, v. $5, n^{\circ} 2$, p. 71-111, 2003.

SACCO DOS ANJOS, F.; CALDAS, Nádia Velleda. O futuro ameaçado: o mundo rural face os desafios da masculinização, envelhecimento e desagrarização. Ensaios FEE, Porto Alegre, v. 26, n.1, p. 661-694, 2005.

SAMPEDRO GALLEGO, R. Género y ruralidad. Las mujeres ante el reto de la desagrarización. Madrid: Ministerio de Trabajo y Asuntos Sociales/Instituto de la Mujer, serie Estudios n 47, 1996.

SCHNEIDER, I. Êxodo, Envelhecimento Populacional e Estratégias de Sucessão na Exploração Agrícola. Indicadores Econômicos, Porto Alegre, v.2, n.4, p.259-268, 1994.

SCHNEIDER, S. Agricultura familiar e industrialização: Pluriatividade e descentralização industrial no Rio Grande do Sul. Porto Alegre: Ed. Universidade/UFRGS, 1999.

SCHNEIDER, S. A diversidade da agricultura familiar Porto Alegre: UFRGS, 2006.

SCHNEIDER, S; CONTERATO, M . A; KOPPE, L . R; SILVA, C.C.

A pluriatividade e as condições de vida dos agricultores

familiares do Rio Grande do Sul. In: SCHNEIDER, Sérgio. A diversidade da agricultura familiar. Porto Alegre: UFRGS, 2006.

SEN, A. Desenvolvimento como liberdade. Companhia das Letras, 2000.

SEYFERTH, G. A Colonização Alemã no Vale do Itajaí-Mirim: um estudo de desenvolvimento econômico. Porto Alegre: Movimento, 1974.

SHIVA, V. Deixe-nos sobreviver: mulheres, ecologia e desenvolvimento. In: RUETHER, R.R. (Org.). Mulheres curando a terra: mulheres do terceiro mundo na Ecologia, no feminismo e na religião. São Paulo: Paulinas, 2000.

SHIVA, V. Biopirataria: a pilhagem da natureza e do conhecimento. Petrópolis: Vozes, 2001. 
SOROKIN, P.; ZIMMERMAN, C. Principles of Rural-Urban Sociology, Nueva York: Henry Holt and Company, 1929.

SYMES, D. Changing gender roles in productionist and post-productionist capitalist agriculture. Journal of Rural Studies, London, v. 7, n 1-2. p. 85-90. 1991.

VÁZQUEZ, F.P; MAZARIEGOS, Josechu V. La implicación de la mujer em la agricultura familiar: apuntes sobre el proceso de desagrarización em España. Política y Sociedad, Madrid, nº 9, p.15-28, 1991.

VEIGA, J.E. Uma Estratégia de Desenvolvimento Rural para o Brasil. Relatório Final do Projeto de Pesquisa e Formação Sindical CUT/CONTAG. São Paulo, 1997.

VEIGA, J.E. O Brasil rural precisa de uma estratégia de desenvolvimento. Brasília: MDA/CNDRS/NEAD, 2001. 